\title{
Rationally repurposed nitroxoline inhibits preclinical models of Epstein-Barr virus-associated lymphoproliferation
}

\author{
Maite Ibáñez de Garayo ${ }^{1,3} \cdot$ Wendi Liu ${ }^{2}$ Nicole C. Rondeau ${ }^{1} \cdot$ Christopher B. Damoci $^{2} \cdot J$ J L. Miranda ${ }^{1}$
}

Received: 17 December 2020 / Revised: 16 March 2021 / Accepted: 4 April 2021 / Published online: 23 June 2021

(c) The Author(s) 2021. This article is published with open access

\begin{abstract}
Repurposing of currently used drugs for new indications benefits from known experience with those agents. Rational repurposing can be achieved when newly uncovered molecular activities are leveraged against diseases that utilize those mechanisms. Nitroxoline is an antibiotic with metal-chelating activity used to treat urinary tract infections. This small molecule also inhibits the function of bromodomain and extraterminal (BET) proteins that regulate oncogene expression in cancer. Lymphoproliferation driven by the Epstein-Barr virus (EBV) depends on these same proteins. We therefore tested the efficacy of nitroxoline against cell culture and small animal models of EBV-associated lymphoproliferation. Nitroxoline indeed reduces cell and tumor growth. Nitroxoline also acts faster than the prototype BET inhibitor JQ1. We suggest that this rational repurposing may hold translational promise.
\end{abstract}

\section{Introduction}

Repurposing of known drugs, also referred to as repositioning, for cancer treatment offers substantial benefits over development of new therapeutic compounds. For example, an established track record of clinical use allows for swifter indication as standard of care because safety profiles already benefit from a wealth of prior experience. While repositioning often occurs through serendipity, rational repurposing may arise when new molecular properties or mechanisms of actions are discovered. We were encouraged by newfound regulation of epigenetics to explore preclinical validation of the small molecule antibiotic nitroxoline for the treatment of lymphoproliferation driven by the Epstein-Barr virus (EBV).

Nitroxoline is an antibiotic prescribed for decades in Europe to treat urinary tract infections [1]. Antibacterial

$\triangle \mathrm{JJ}$ L. Miranda

jj@jjmirandalab.org

1 Department of Biology, Barnard College, Columbia University, New York, NY 10027, USA

2 Herbert Irving Comprehensive Cancer Center, Columbia University Irving Medical Center, New York, NY 10032, USA

3 Present address: Department of Pathology and Laboratory Medicine, Weill Cornell Medical College, New York, NY 10065, USA activity can be attributed to the compound's ability to chelate metal ions [2,3] and dispel biofilms [4]. Years of use has led to a good understanding of nitroxoline pharmacokinetics [5]. A high-throughput screen discovered inhibition of human cell proliferation and subsequent work in mouse models of cancer revealed related efficacy against human urothelial carcinoma and invasive ductal carcinoma xenografts [6]. Potential antitumor properties include the ability to inhibit methionine aminopeptidase [6] and cathepsin B [7]. Efforts at repurposing nitroxoline have uncovered molecular mechanisms of anticancer activity $[8,9]$ and succeeded against human xenografts in mouse models of clear cell renal cell carcinoma [10], multiple myeloma [11], and glioma [12]. A more recent highthroughput screen identified nitroxoline as a competitive inhibitor of the bromodomain and extraterminal (BET) family of chromatin regulators [13]. This new molecular activity suggests repurposing against cancers that leverage these particular epigenetic proteins for proliferation.

EBV immortalizes B cells by co-opting BET protein function. Epigenetic deregulation during cancer results in the formation of super-enhancers dependent on BET proteins such as BRD4 to drive the expression of oncogenes [14]. Infection by EBV can similarly assemble super-enhancers consisting of viral proteins and BRD4 [15]. These viral proteins are expressed in what is termed type III EBV latency, a stereotyped transcription program found in most cases of EBV-associated posttransplant lymphoproliferative 
disease (PTLD) [16]. The prototype BET inhibitor JQ1 reduces growth of EBV-associated lymphoproliferation in cell culture $[15,17]$; we also further demonstrated efficacy in a mouse model [17]. Unfortunately, no BET inhibitors are approved for clinical use [18]. We therefore hoped to help validate the repurposing of the antibiotic nitroxoline against EBV-associated lymphoproliferation.

Lymphoblastoid cell lines (LCLs) serve as a model of EBVassociated lymphoproliferation similar to that observed in PTLD. We grew the EBV-positive GM12878 and 721 LCLs in culture [17, 19]. GM12878 is a suspension cell line without translocations that was derived from B lymphocytes transformed by EBV and is frequently examined in epigenetic studies [20]; 721 was derived independently but similarly [21]. The type III viral latency transcription programs of GM12878 and 721 LCLs [19] match those observed in most cases of
EBV-associated PTLD [16]. We treated cells with nitroxoline (Sigma-Aldrich, St. Louis, MO, USA), JQ1 (Selleck Chemicals, Houston, TX, USA), or a DMSO vehicle control as previously described for JQ1 [17]. Proliferation was measured by counting cells. Viability was measured with trypan blue, which detects membrane integrity. Metabolic activity was measured with PrestoBlue Cell Viability Reagent (Thermo Fisher Scientific, Waltham, MA, USA), which detects reducing power. Cell counts and trypan blue exclusion were measured on a Countess II FL Automated Cell Counter (Thermo Fisher Scientific, Waltham, MA, USA) after seeding GM12878 cells

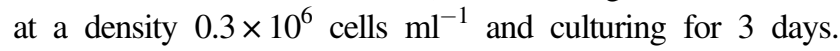
PrestoBlue Cell Viability Reagent was measured on a Spark multimode microplate reader (Tecan, Männedorf, Switzerland) at an absorbance wavelength of $570 \mathrm{~nm}$ after seeding GM12878 or 721 cells at a density $0.1 \times 10^{6}$ cells ml $^{-1}$ and
Fig. 1 Nitroxoline reduces proliferation of EBVimmortalized LCLs in cell culture. a Growth of the GM12878 line in cell culture after 3 days of nitroxoline treatment. Expansion is measured as cell density increase normalized to the vehicle control. Error bars represent the standard deviation of $n=4$ replicates. b Viability of the GM12878 line in cell culture after 3 days of nitroxoline treatment.

Membrane integrity is measured as trypan blue exclusion normalized to the vehicle control. Error bars represent the standard deviation of $n=4$ replicates. c Metabolic activity of the GM12878 and 721 lines in cell culture after up to 3 days of nitroxoline or JQ1 treatment. Reducing power is measured as PrestoBlue Cell Viability Reagent absorbance normalized to the vehicle control. Error bars represent the standard deviation of $n=4$ replicates a

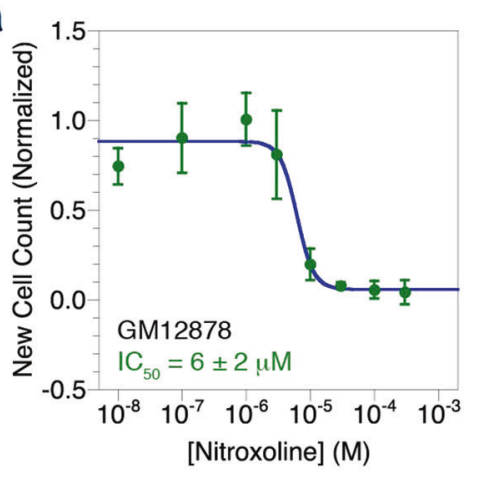

C
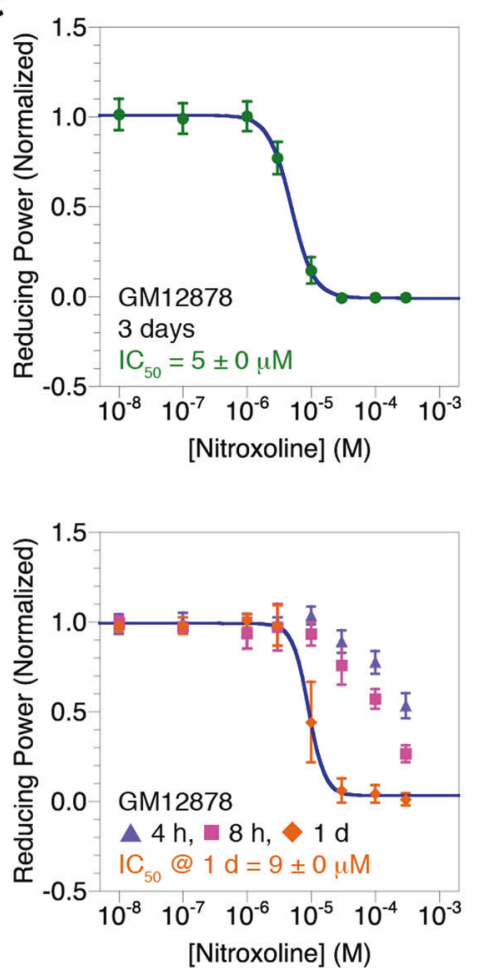

b
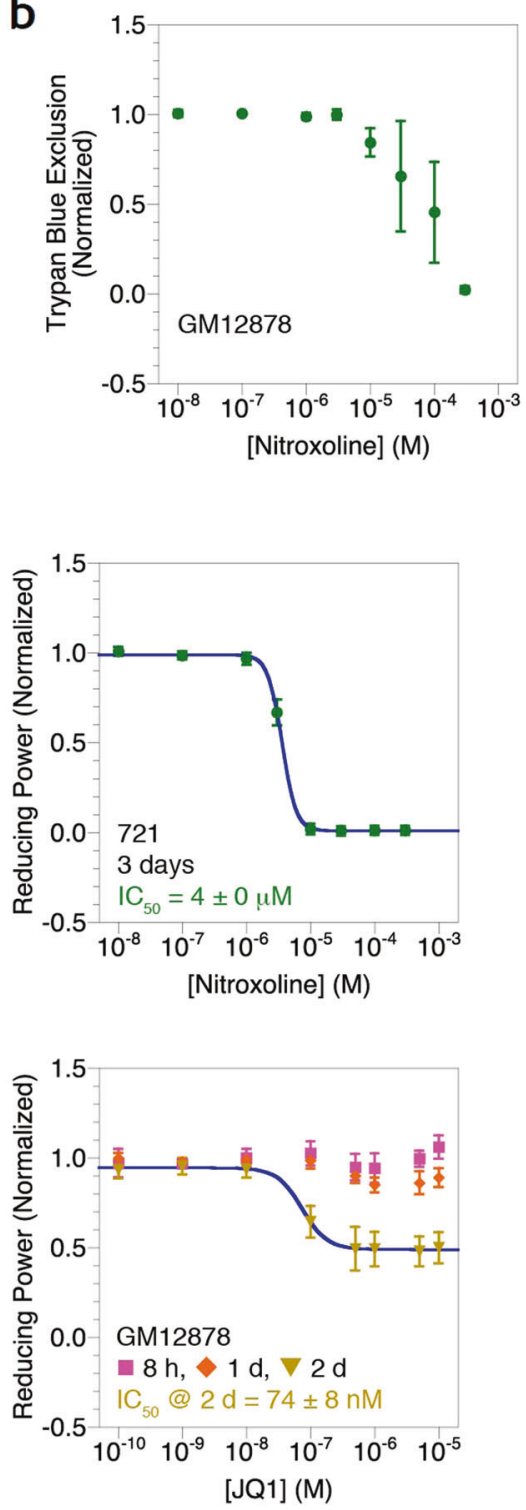
culturing for up to 3 days. Statistical comparisons were made with paired Student's $t$ tests.

Nitroxoline reduces growth of EBV-associated lymphoproliferation in cell culture. Nitroxoline reduces growth of the GM12878 LCL by decreasing the proliferation of new cells (Fig. 1a), decreasing viability (Fig. 1b), and decreasing metabolic activity (Fig. 1c). Viability is perturbed at a higher concentration than proliferation and metabolic activity because membrane integrity is usually impacted at a later stage of cell death than cell count and reducing power. To demonstrate generality, nitroxoline also decreases metabolic activity of the 721 LCL (Fig. 1c). These effects are observed at low $\mu \mathrm{M}$ concentrations achievable in humans $[22,23]$. We previously demonstrated that the prototype BET inhibitor JQ1 reduces growth of GM12878 cells both in cell culture and in a mouse model [17]. To compare nitroxoline with JQ1, we measured metabolic activity of GM12878 cells over a time course (Fig. 1c). Nitroxoline reduces metabolic activity much more potently than JQ1 under these conditions. After $8 \mathrm{~h}$ and 1 day, JQ1 shows very little effect on reducing power, only achieving substantial growth inhibition after 2 days. Nitroxoline shows moderate effects after $8 \mathrm{~h}$ and even as early as $4 \mathrm{~h}$, achieving substantial growth inhibition after 1 day. Nitroxoline therefore acts with faster kinetics than JQ1. Encouraged by these results in cell culture, we then tested the efficacy of nitroxoline in a small animal model of cancer.
We assessed efficacy in a mouse model with LCL xenografts as previously described for JQ1 [17]. Nitroxoline was suspended in soybean oil for dosing. Weight was also measured in addition to tumor size. Statistical comparisons were made with Mann-Whitney-Wilcoxon rank sum tests.

Nitroxoline reduces growth of EBV-associated lymphoproliferation in a small animal model. A dose of $80 \mathrm{mg} \mathrm{kg}^{-1}$ intraparietal nitroxoline daily reduces tumor sizes after $\sim 2$ weeks (Fig. 2a). Tumor volume decreases by $\sim 40 \%$. No toxicity is observed during the time course as weight, a gross indicator of health, is not affected by nitroxoline treatment (Fig. 2b). A lower dose of $40 \mathrm{mg} \mathrm{kg}^{-1}$ intraparietal nitroxoline daily also reduces tumor sizes by $\sim 40-50 \%$ after $\sim 2$ weeks (Fig. 2a) without weight loss (Fig. 2b).

We cautiously note that we did observe statistically insignificant mortality in the nitroxoline group with extended treatment. Prolonged dosing beyond the $\sim 2$-week time frame of tumor size reduction without mortality (Fig. 2a) resulted in loss of mice. With $80 \mathrm{mg} \mathrm{kg}^{-1}$ nitroxoline, two out of eight mice did not survive, one lost on day 15 and another on day 21. With $40 \mathrm{mg} \mathrm{kg}^{-1}$ nitroxoline, one out of eight mice did not survive, lost on day 19. These differences in survival were not significant according to a Fisher exact test. The cause of mortality is unclear given the lack of weight loss up to (Fig. 2b) and inclusive of those time points (data not shown). No abnormal findings were observed during animal care (data not shown). We find it difficult to speculate with confidence that either BET inhibition or metal chelation is related
Fig. 2 Nitroxoline reduces proliferation of EBVimmortalized LCLs in an animal model. a Expansion of engrafted GM12878 cells in NSG mice treated with nitroxoline.

Expansion is measured as tumor volume. Error bars represent the standard deviation of $n=8$ mice. $\mathbf{b}$ Health of NSG mice treated with nitroxoline. Health is measured as weight. Error bars represent the standard deviation of $n=8$ mice a

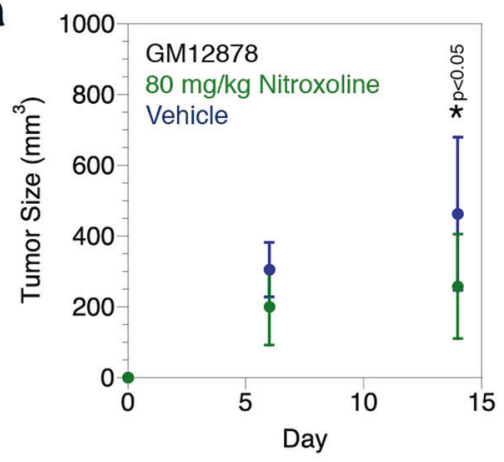

b

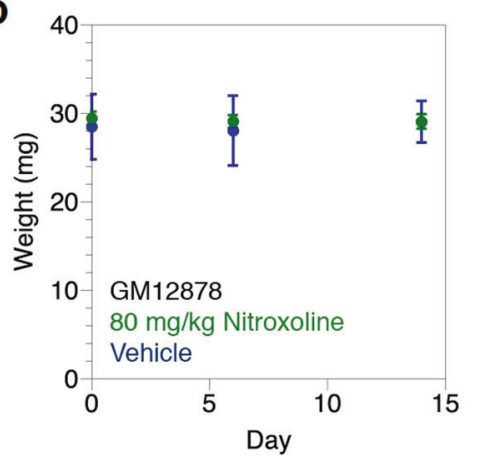

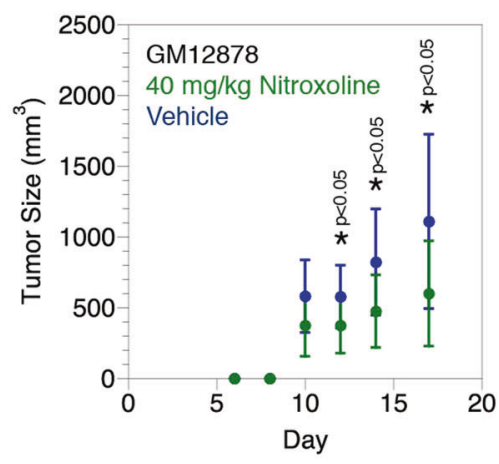

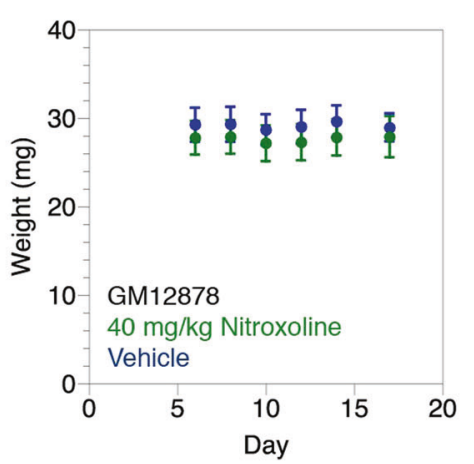


to mouse death. Technical error during repeated intraperitoneal dosing is possible. Other experiments treating mice with nitroxoline at higher doses for longer times also showed no increased mortality compared to vehicle [10]. Additional investigation into the long-term safety profile of nitroxoline may nonetheless be necessary.

Even though work remains, PTLD treatment strategies could benefit from additional options [24, 25]. A rationally repurposed drug may allow safe and rapid translation into the clinic. Nitroxoline indeed reduces the growth of EBV-associated lymphoproliferation in both cell culture and a mouse model. We contend that our preclinical studies support usage of the antibiotic nitroxoline against EBVassociated malignancies as seen in PTLD.

Acknowledgements The authors would like to acknowledge the Columbia University Medical Center Cancer Center Support Grant, NIH grant P30CA013696 from the National Cancer Institute, which partially funds the Oncology Precision Therapeutics and Imaging Core Shared Resource.

\section{Compliance with ethical standards}

Conflict of interest The authors declare no competing interests.

Publisher's note Springer Nature remains neutral with regard to jurisdictional claims in published maps and institutional affiliations.

Open Access This article is licensed under a Creative Commons Attribution 4.0 International License, which permits use, sharing, adaptation, distribution and reproduction in any medium or format, as long as you give appropriate credit to the original author(s) and the source, provide a link to the Creative Commons license, and indicate if changes were made. The images or other third party material in this article are included in the article's Creative Commons license, unless indicated otherwise in a credit line to the material. If material is not included in the article's Creative Commons license and your intended use is not permitted by statutory regulation or exceeds the permitted use, you will need to obtain permission directly from the copyright holder. To view a copy of this license, visit http://creativecommons. org/licenses/by/4.0/.

\section{References}

1. Naber KG, Niggemann H, Stein G, Stein G. Review of the literature and individual patients' data meta-analysis on efficacy and tolerance of nitroxoline in the treatment of uncomplicated urinary tract infections. BMC Infect Dis. 2014;14:628.

2. Pelletier C, Prognon P, Bourlioux P. Roles of divalent cations and $\mathrm{pH}$ in mechanism of action of nitroxoline against Escherichia coli strains. Antimicrob Agents Chemother. 1995;39:707-13.

3. Gale EF. The assimilation of amino-acids by bacteria; trace metals in glutamic acid assimilation and their inactivation by 8-hydroxyquinoline. J Gen Microbiol. 1949;3:369-86.

4. Sobke A, Klinger M, Hermann B, Sachse S, Nietzsche S, Makarewicz $\mathrm{O}$, et al. The urinary antibiotic 5-nitro-8hydroxyquinoline (nitroxoline) reduces the formation and induces the dispersal of Pseudomonas aeruginosa biofilms by chelation of iron and zinc. Antimicrob Agents Chemother. 2012;56:6021-5.

5. Mrhar A, Kopitar Z, Kozjek F, Presl V, Karba R. Clinical pharmacokinetics of nitroxoline. Int J Clin Pharm Biopharm. 1979; 17:476-81.

6. Shim JS, Matsui Y, Bhat S, Nacev BA, Xu J, Bhang HC, et al. Effect of nitroxoline on angiogenesis and growth of human bladder cancer. J Natl Cancer Inst. 2010;102:1855-73.

7. Mirković B, Markelc B, Butinar M, Mitrović A, Sosič I, Gobec S, et al. Nitroxoline impairs tumor progression in vitro and in vivo by regulating cathepsin B activity. Oncotarget. 2015;6:19027-42.

8. Mitrović A, Kos J. Nitroxoline: repurposing its antimicrobial to antitumor application. Acta Biochim Pol. 2019;66:521-31.

9. Shim JS, Liu JO. Recent advances in drug repositioning for the discovery of new anticancer drugs. Int J Biol Sci. 2014;10:654-63.

10. Zhang QI, Wang S, Yang D, Pan K, Li L, Yuan S. Preclinical pharmacodynamic evaluation of antibiotic nitroxoline for anticancer drug repurposing. Oncol Lett. 2016;11:3265-72.

11. Mao H, Du Y, Zhang Z, Cao B, Zhao J, Zhou H, et al. Nitroxoline shows antimyeloma activity by targeting the TRIM25/p53 axle. Anticancer Drugs. 2017;28:376-83.

12. Kumari N, Thakur N, Cho HR, Choi SH. Assessment of early therapeutic response to nitroxoline in temozolomide-resistant glioblastoma by amide proton transfer imaging: a preliminary comparative study with diffusion-weighted imaging. Sci Rep. 2019;9:5585.

13. Jiang H, Xing J, Wang C, Zhang H, Yue L, Wan X, et al. Discovery of novel BET inhibitors by drug repurposing of nitroxoline and its analogues. Org Biomol Chem. 2017;15:9352-61.

14. Lovén J, Hoke HA, Lin CY, Lau A, Orlando DA, Vakoc CR, et al Selective inhibition of tumor oncogenes by disruption of superenhancers. Cell. 2013;153:320-34.

15. Zhou H, Schmidt SCS, Jiang S, Willox B, Bernhardt K, Liang J, et al. Epstein-Barr virus oncoprotein super-enhancers control B cell growth. Cell Host Microbe. 2015;17:205-16.

16. Hopwood P, Crawford D. The role of EBV in post-transplant malignancies: a review. J Clin Pathol. 2000;53:248-54.

17. He A, Miranda JL. JQ1 reduces Epstein-Barr virus-associated lymphoproliferative disease in mice without sustained oncogene repression. Leuk Lymphoma. 2018;59:1248-51.

18. Andrieu G, Belkina AC, Denis GV. Clinical trials for BET inhibitors run ahead of the science. Drug Discov Today Technol. 2016;19:45-50.

19. Phan AT, Fernandez SG, Somberg JJ, Keck KM, Miranda JL. Epstein-Barr virus latency type and spontaneous reactivation predict lytic induction levels. Biochem Biophys Res Commun. 2016;474:71-5.

20. ENCODE Project Consortium. An integrated encyclopedia of DNA elements in the human genome. Nature. 2012;489:57-74.

21. Kavathas P, Bach FH, DeMars R. Gamma ray-induced loss of expression of HLA and glyoxalase I alleles in lymphoblastoid cells. Proc Natl Acad Sci USA. 1980;77:4251-5.

22. Jacobs MR, Robinson RG, Koornhof HJ. Antibacterial activity of nitroxoline and sulphamethizole alone and in combination in urinary tract infections. S Afr Med J. 1978;54:959-62.

23. Sorel RH, Snelleman C, Hulshoff A. High-performance liquid chromatographic analysis of nitroxoline in plasma and urine. $\mathrm{J}$ Chromatogr. 1981;222:241-8.

24. DeStefano CB, Desai SH, Shenoy AG, Catlett JP. Management of post-transplant lymphoproliferative disorders. $\mathrm{Br} \mathrm{J}$ Haematol. 2018;182:330-43.

25. Dierickx D, Habermann TM. Post-transplantation lymphoproliferative disorders in adults. N Engl J Med. 2018;378:549-62. 